\title{
Seltene Lutherbibel mit bemerkenswerten Holzschnitten
}

Bei der Stuttgarter Antiquariatsmesse 2014 konnte ein gut erhaltenes Exemplar einer sonst nur in zwei Schweizer Bibliotheken nachgewiesenen Bibelausgabe erworben werden. Es handelt sich um die zweite Auflage der bebilderten Lutherbibel, die 1707 vom Verlag Brandmüller gedruckt wurde (Bb deutsch 1707 02). Bemerkenswert sind die abweichenden Angaben zum Druckort auf dem Gesamttitelblatt (Frankfurt) bzw. auf dem Zwischentitelblatt vor dem Neuen Testament (Basel). Wechselnde Druckorte begegnen auch in späteren Bibeldrucken dieses Verlegers (Frankfurt 1719: B deutsch 1719 01; Basel 1747: Bb deutsch 1747 01). Wanderungen von Druckern und Illustratoren waren in der frühen Neuzeit nicht unüblich (z.B. Christoph Wust in Wittenberg und Frankfurt).

Bedeutsam ist, dass sich die Lutherbibel im reformierten Kontext der Deutschen Schweiz neben der Zürcher Bibel behaupten kann. Um sich von der Konkurrenz der im deutschen Sprachraum den Bibeldruck bestimmenden Verleger Endter (Nürnberg) und Stern (Lüneburg) abzusetzen, greift das Haus Brandmüller auf bis dahin nirgendwo verwendete Holzschnittfolgen zu biblischen Szenen zurück - und das etwa 150 Jahre nach deren Entstehung.

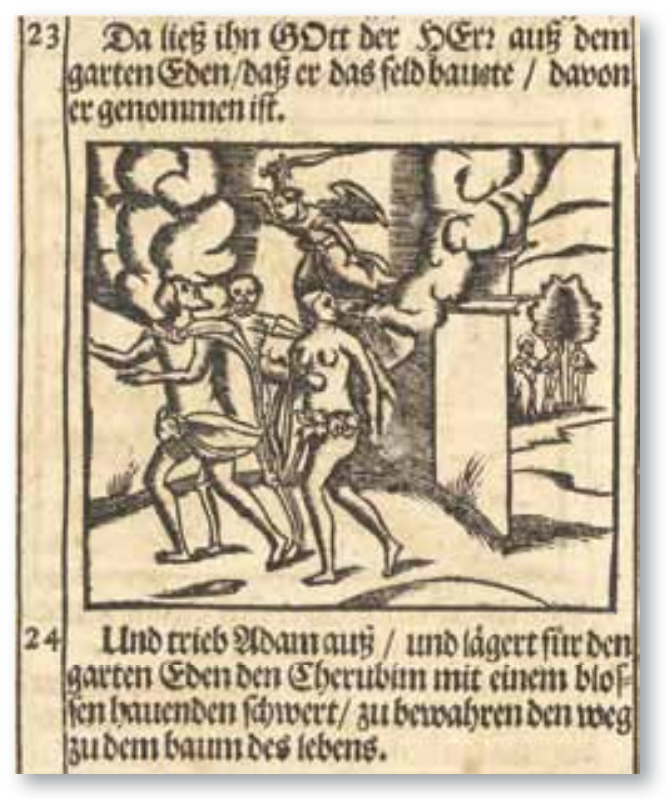

Es handelt sich um lediglich spaltenbreite und eher einfache Bilder des 1545-1559 in Bern und Basel tätigen Formschneiders und Schönschreibmeisters Heinrich Holzmüller. ${ }^{1}$ Calvinistische Skepsis gegenüber bildlicher Darstellbarkeit Gottes wirkt sich so aus, dass Gott in den Holzschnitten durch das Tetragramm (JHWH) repräsentiert, nicht aber figürlich-anthropomorph angedeutet wird. Die Bilder spitzen komplexe Inhalte auf wichtige Einzelaspekte zu. So wird die Auswirkung des Sündenfalls - charakteristisch für reformatorische Theologie - so betont, dass das aus dem Paradies vertriebene erste Menschenpaar vom Tod (Skelett) in Empfang genommen wird. Ungewöhnlich ist die Einordnung der alttestamentlichen Apokryphen als Anhang hinter dem Neuen Testament statt wie sonst üblich zwischen den Testamenten.

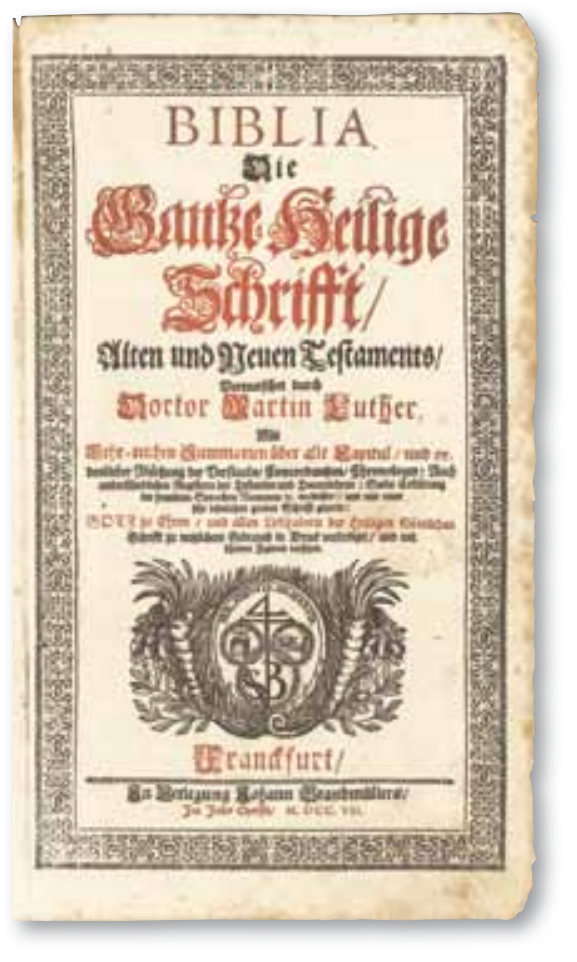

Der eigentliche Bibeltext wird ergänzt durch Summarien am Kapitelanfang, Parallelstellen, Register sowie durch Luthers Vorreden zum Alten und Neuen Testament. Außer den Bild-Holzschnitten begegnen noch Holzschnitt-Initialen an Kapitelanfängen. Der originale Schweinslederband ist mit ornamentalen Blindprägestempeln verziert und verfügt über Metallbeschläge sowie Schließen.

\section{Christian Herrmann}

